\title{
CROSSFLOW ULTRAFILTRATION FOR REMOVING DIRECT-15 DYE FROM WASTEWATER OF TEXTILE INDUSTRY
}

\author{
A.L. Ahmad*, S.W. Puasa, and S. Abiding \\ School Of Chemical Engineering, Universiti Sains Malaysia, Engineering Campus, Seri \\ Ampangan, 14300 Nibong Tebal, Penang, Malaysia
}

Received 31 August 2005

\begin{abstract}
Ultrafiltration membrane was used to treat the effluent from textile industries. Crossflow ultrafiltration using GN polymeric membrane was used to remove the dye from textile effluent. A synthetic textile effluent of Direct-15 dye was used. The study focused through the effect of feed concentration, transmembrane pressure and solution's $\mathrm{pH}$ on the permeate flux and percentage of dye removal were investigated. Dye concentration had significant effects on flux values. Under the fixed pressures and $\mathrm{pH}$, the flux decreased while the dye rejection increased with increasing feed concentration. Transmembrane pressure also had significant effect on flux values. Under the fixed feed concentration and $\mathrm{pH}$, the flux increased while dye rejection decreased with increasing pressure. Experiment data showed that the highest flux was observed at $\mathrm{pH} 4$ (acidic condition) while the highest dye removal observed at $\mathrm{pH}$ 7. Data collection could be used to improve the effectiveness of dye removal from textile industry wastewater using membrane technology.
\end{abstract}

Keywords: Ultrafiltration, membrane separation, dye, crossflow ultrafiltration, cake resistance

\section{INTRODUCTION}

The world population is ever increasing putting a considerable amount of stress on the environment. Water will continue to become major factor for the survival of humans and human activities. This is especially true in the industrialized areas. At present, approximately $50 \%$ of water is being used by households, and other $50 \%$ for industrial and agricultural activities. However, with an increasing population, there will be pressure for industries to reclaim and reuse some of its wastewater. This is due to the combine pressures of increasing water and wastewater costs and increasing stringent regulatory requirements of discharged wastewater [1].

Homemade textile industry is very well known in Malaysia especially in the East Cost of Peninsular Malaysia and Sarawak. Today, this industry has become very commercialized and contributed positively to the economic growth for some states such as Kelantan and Terengganu. Traditionally, the process of making a batik industry is shown in Fig. 1 [2].

Textile industries are including as one of the major water consumers and the source of considerable solution. The environmental challenge for the textile industry is associated with liquid waste, which tends to dominate over air-emissions and solid wastes in terms of

\footnotetext{
*Corresponding author e-mail: chlatif@eng.usm.my
} 
environmental effects. The wastewaters from printing and dyeing units in textile plant are often rich in color, containing residual of dyes and chemical, and needs proper treatment before releasing into the environment [3].

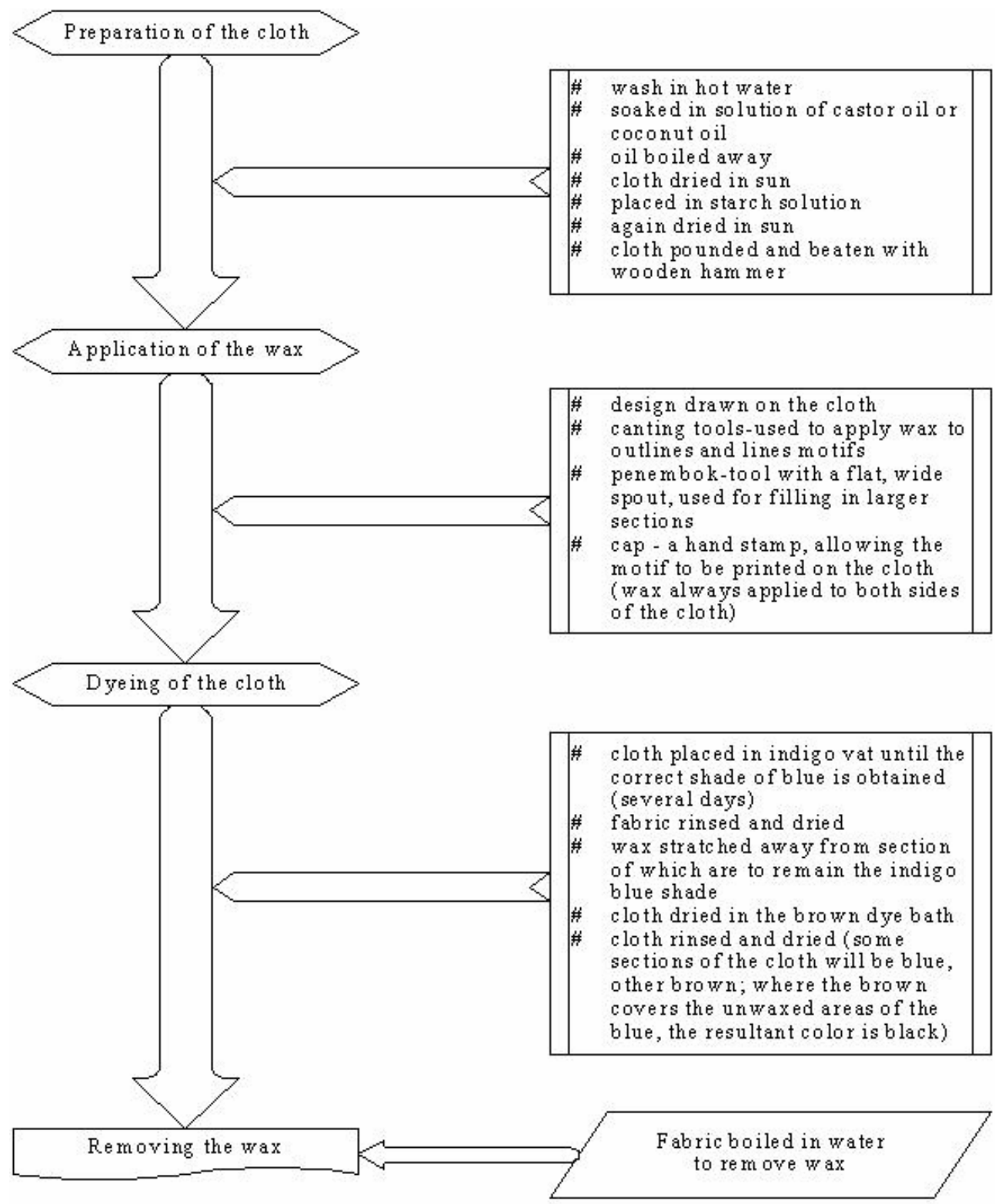

Fig. 1: Schematic diagram of a batik process [2]

Dyeing process used both organic and inorganic synthetic dye that available in variety of colours. Chemical agent used for dye bond to the cloth. The dye reacts with the chemical agent to produce the final colour. Dye residue recharged during the dyeing process is the major pollutant in this industry. It produces a variety of wastewater streams that vary widely with respect to parameters such as grease surfactant contains suspended solids and colours. On the other hand, the dye which presents bring a problem in waters where the heavy metals incorporated in the dye and the salt will cause a toxicity problem when discharged to 208 
environment [2]. Thus, while rewarding a most profitable commodity, the adverse environmental impact from the textile industry cannot be ignored.

Resistance of dyes to biological degradation has made color removal from textile wastewater difficult, as they are not readily degraded under the aerobic conditions prevailing in biological treatment plant [4]. The color of textile effluent is unacceptable under Malaysian Environmental Regulation besides the other parameter such as Chemical Oxygen Demand (COD), Biological Oxygen Demand (BOD), total iron, etc [1].

Due to these factors, the textile industry faces the challenge of balancing the environmental protection, its economic viability and sustainable development. There is an urgent need to find a way to preserve the environment while keeping the economic growing.

Several innovative treatment technologies have been developed and applied in order to treat textile effluent. The most widely used treatment systems are conventional activated sludge. This system poorly removes the widely used dyes, and is clearly ineffective in decolourising textile effluent, even when mixed and treated together with sewage. Activated Carbon is the most commonly used and most successful adsorbent. However, it is expensive and the level of color removal depends on the dye type. Also, 100\% color removal is rarely achieved. Ozone has been shown to have the ability to breakdown most dyes. However, even high doses of ozone do not completely mineralize the organic dye to carbon dioxide and water. This due to the decolourisation rate decreasing with increasing initial dye colour [5].

Treatment of textile effluent nowadays requires a sound and efficient system in facing the current challenges. Membrane technology could be one of such promising technology which able to treat textile effluent in a more beneficial way. Although filtration techniques require an initial high setup cost, it is overweighed by the significant cost saving achieved through reuse of permeate.

There are a number of studies that have been conducted for treating various types of wastewater by using membrane technology for the purpose of treating, recovery and recycling of water. Koyuncu [4] studied nanofiltration to treat Reactive Orange 16 solution where the experiments were operated at crossflow filtration mode. They succeed achieving rejection coefficient higher than $99 \%$ in optimal conditions of pressure, feed concentration, and cross flow velocity. Tang and Chen [5] studied nanofiltration to treat CI reactive Black 5 containing in textile wastewater. Working at low pressures up to $500 \mathrm{kPa}$, relatively high fluxes were obtained, with an average dye rejection of $98 \%$ and $\mathrm{NaCl}$ rejections of less than $14 \%$. A high quality of reuse water could be recovered.

With environment regulation tighten, ultrafiltration (UF) offers several varied application covering many aspect of textile processing. In the textile industry, ultrafiltration can be used for treating size and latex contaminant effluents, treating the effluents from wool washing and treating wastewater from dyeing process. Ultrafiltration is capable of completely separating many dyes such as vat, acid, dispersed, mordant and direct dyes from the brine. Some dye manufacturers use UF to wash excess salt out of the dyes. Although ultrafiltration achieves complete colour removal for all classes of dye, care is needed to avoid membrane clogging which appears to occur rapidly [6].

In this study, GN polymeric ultrafiltration (UF) membrane treatment of dye solution containing Direct-15 dye has been evaluated to remove color. The effects of significant parameters such as initial feed concentration, transmembrane pressures and solution's $\mathrm{pH}$ on the permeate flux and percentage of dye removal which applied to the crossflow or continuous runs were investigated.

\section{MATERIAL AND METHODS}

The Direct-15 dye was used and was obtained from Sigma Aldrich (M) Sdn. Bhd, Malaysia. 
Dye solution was prepared at $25^{\circ} \mathrm{C}$ for certain concentration by dissolving certain amount of dye into deionized water. $\mathrm{NaOH}$ or $\mathrm{HCl}$ solutions were used as $\mathrm{pH}$ adjustment for filtration process at certain required $\mathrm{pH}$.

Table 1: Membrane specification

\begin{tabular}{cccccc}
\hline Type & Membrane & $\begin{array}{c}\text { Pore Size } \\
\text { (MWCO) }\end{array}$ & $\begin{array}{c}\text { Typical Operating } \\
\text { Pressure }\end{array}$ & Recommended pH & $\begin{array}{c}\text { Maximum } \\
\text { Temperature }\end{array}$ \\
\hline GN & $\begin{array}{l}\text { TF (Thin Film) } \\
\text { UF membrane }\end{array}$ & \multirow{2}{*}{10,000} & $\begin{array}{c}40-200 \mathrm{psig} \\
(276-1379 \mathrm{kPa})\end{array}$ & $\begin{array}{c}\text { Operating range }: 2-11 \\
\text { Cleaning range }: 2.0-11.5\end{array}$ & $\begin{array}{c}122^{\circ} \mathrm{F} \\
\left(50^{\circ} \mathrm{C}\right)\end{array}$ \\
\hline
\end{tabular}

The membrane used in this study was GN polymeric membrane supplied by Osmonics. Properties of this membrane were given in Table 1. The experiment was operated at cross flow filtration mode (continuous process) and was run for one hour for each variable concentration. The flux was recorded by measuring the filtrate volume collected for every 10 minutes. The average of 5 experimental reading was taken. Permeate were collected every 10 minutes and its absorbance was analyzed using a Spectronic 20D spectrophotometer at wavelength of $575 \mathrm{~nm}$ for Direct-15 dye. Their absorbance reading from the spectrophotometer was measured and compared to the calibration graph of known concentration $(0 ; 5 ; 10 ; 15 ; 20 \mathrm{ppm})$ to calculate the actual concentration of the dye in permeate system. Solution's $\mathrm{pH}$ was measured by an ORION SA 720 type $\mathrm{pH}$ meter. The permeation test rig is shown in Fig. 2.

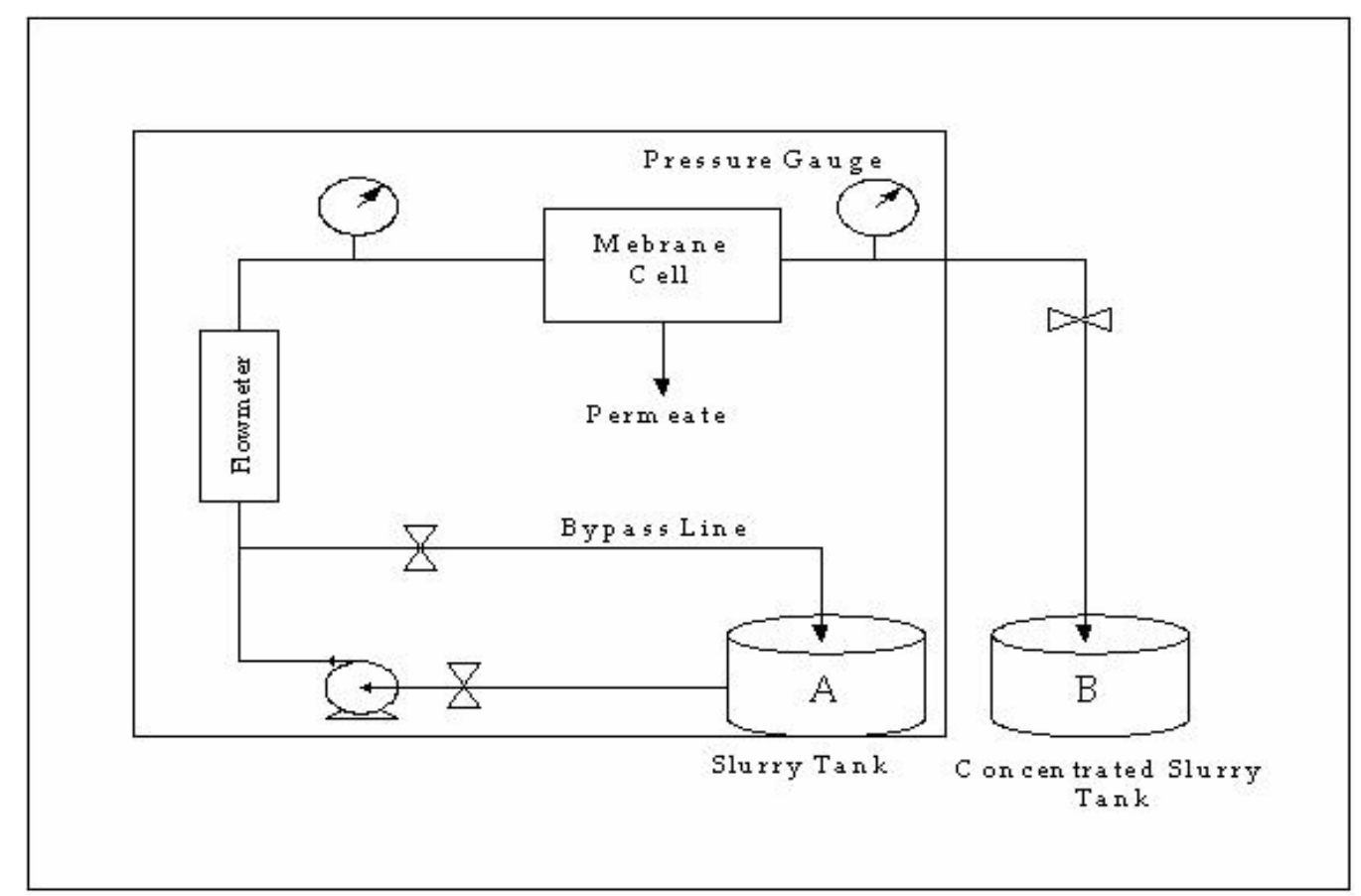

Fig. 2: Permeation test-rig

\section{RESULTS AND DISCUSSION}

\subsection{Effects of feed concentration}

Feed concentration plays a significant role in ultrafiltration membrane separation. The GN polymeric membrane was tested with different dye concentrations at constant pressure and $\mathrm{pH}$ 210 
to determine dye removal. Direct-15 dye concentrations of $5 \mathrm{ppm}, 10 \mathrm{ppm}, 15 \mathrm{ppm}$ and $20 \mathrm{ppm}$ were studied at pressure $18.2 \mathrm{psia}$ and $\mathrm{pH}$ 7. Initially, the experiment was tested with water-freedye to calculate the water flux. Result showed that the average water flux was $2.989 \times 10^{-3}$ $\mathrm{m}^{3} / \mathrm{m}^{2} . s$.

Table 2 shows the average flux and the average rejection for cross flow ultrafiltration recovery of dye at different feed concentrations. It clearly shows that when the feed concentration of dye increased from $5 \mathrm{ppm}$ to $10 \mathrm{ppm}$, the average flux slightly decreased from $2.783 \times 10^{-3} \mathrm{~m}^{3} / \mathrm{m}^{2}$.s to $2.651 \times 10^{-3} \mathrm{~m}^{3} / \mathrm{m}^{2}$.s. Time-dependent fluxes of the experiment are shown in Fig. 3. This figure shows that dye concentration had a significant effect on the flux where the flux value decreased with increasing time and dye concentration. This may cause by the dye adsorption on the membrane surface which due to the increased polarization of the dyes at the feed-membrane interface; thus the higher probability of membrane pore blocking and fouling to occur $[4,5,7]$.

Table 2: Average flux and average rejection at different concentration of dye $(P=18.7$ psia, $\mathrm{pH}=7$ )

\begin{tabular}{|c|c|c|}
\hline Dye concentration (ppm) & Average flux $\times 10^{3}\left(\mathrm{~m}^{3} / \mathrm{m}^{2} . \mathrm{s}\right)$ & Average rejection (\%) \\
\hline 5 & 2.783 & 49.63 \\
\hline 10 & 2.651 & 65.76 \\
\hline 15 & 2.594 & 71.8 \\
\hline 20 & 2.479 & 78.95 \\
\hline
\end{tabular}

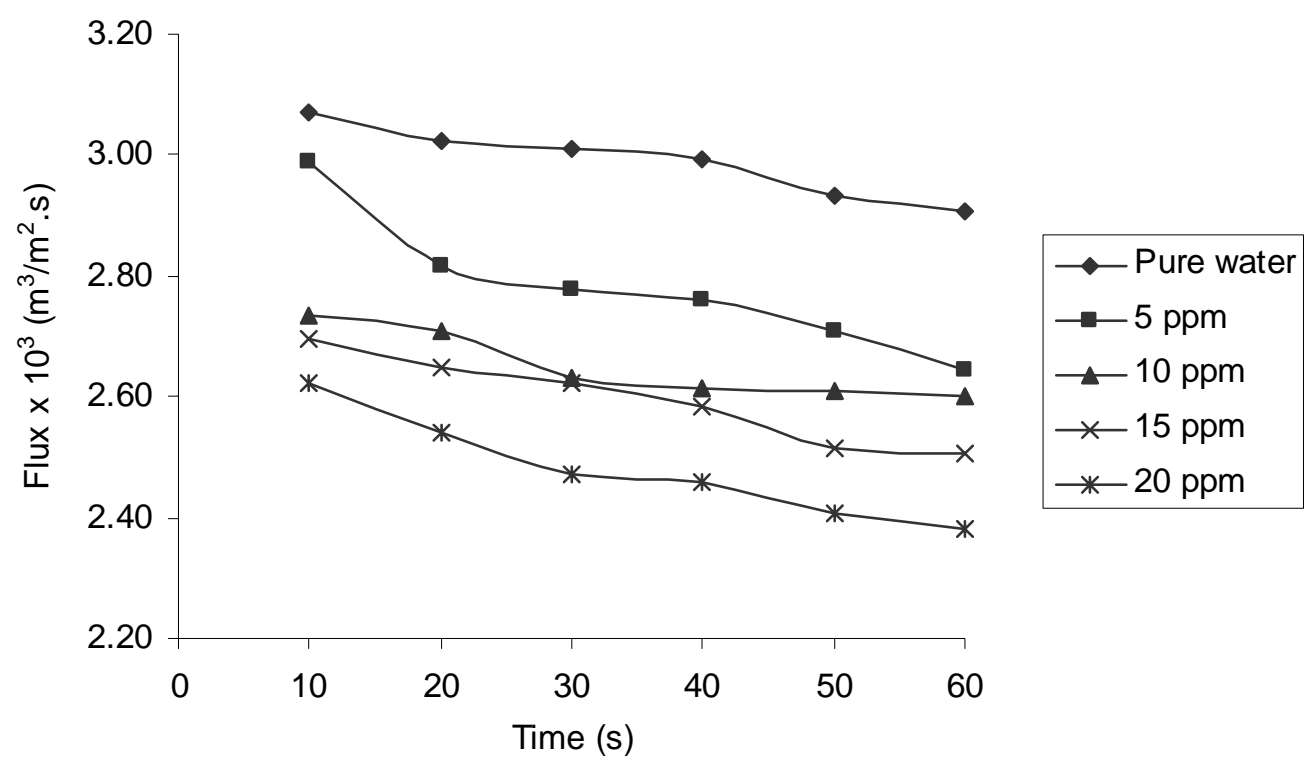

Fig. 3: Flux at different concentration of dye versus time $(P=18.7$ psia, $p H=7)$

As the feed concentration increased, more dye particles would be collected on the surface of the membrane which increased the fouling, reduced the flux while increased the percentage of dye rejection. On the other hand, the average percentage of dye rejection increased as the feed concentration increased. From Table 2, it clearly shows when the feed concentration increased from $5 \mathrm{ppm}$ to $10 \mathrm{ppm}$, the average percentage of dye rejection increased from $49.63 \%$ to $65.76 \%$. 
Figure 4 shows the pattern of rejection at different feed concentration versus time. This figure clearly shows that the percentages of the dye rejection increased with increasing time and feed concentration. This was due to the faster formation of cake on the membrane surface. A gel layer form by the rejected dye on membrane surface may operate as an additional resistance to the permeation of dyes due to complete rejection of dyes. Permeation of dyes for the high concentration was higher. Higher dye concentration increased the dye accumulation on membrane surface and color removal became higher than those of the lower dye concentrations [4].

The cake resistance, $R_{C}$ was calculated using Eq. (1) depending on data collected from the experiments which the results shown in Table 2.

$$
J_{V}=\frac{\Delta P}{\mu\left(R_{m}+R_{C}\right)}
$$

where:

$$
\begin{array}{ll}
J_{V} & \text { Flux, } \mathrm{m} / \mathrm{s} \\
\Delta P & \text { Transmembrane pressure difference, } \mathrm{Pa} \\
\mu & \text { Viscosity of the filtrate, Pa.s } \\
R_{m} & \text { Membrane Resistance, } \mathrm{m}^{-1} \\
R_{C} & \text { Cake Resistance, } \mathrm{m}^{-1}
\end{array}
$$

The membrane resistance, $R_{m}$ was calculated by using average water flux value as the cake resistance, $R_{C}$ is set to zero (water-free-dye). From equation (1), the value of $R_{m}$ calculated is $8.853 \times 10^{9} \mathrm{~m}^{-1}$.

Table 3 shows that the cake resistance increases with the increase of initial dye concentration. It clearly shows that when the feed concentration of dye increased from $5 \mathrm{ppm}$ to $10 \mathrm{ppm}$, the $R_{C}$ value slightly increased from $4.060 \times 10^{10} \mathrm{~m}^{-1}$ to $4.307 \times 10^{10} \mathrm{~m}^{-1}$. Further dye concentration increment also had slightly increased the cake resistance.

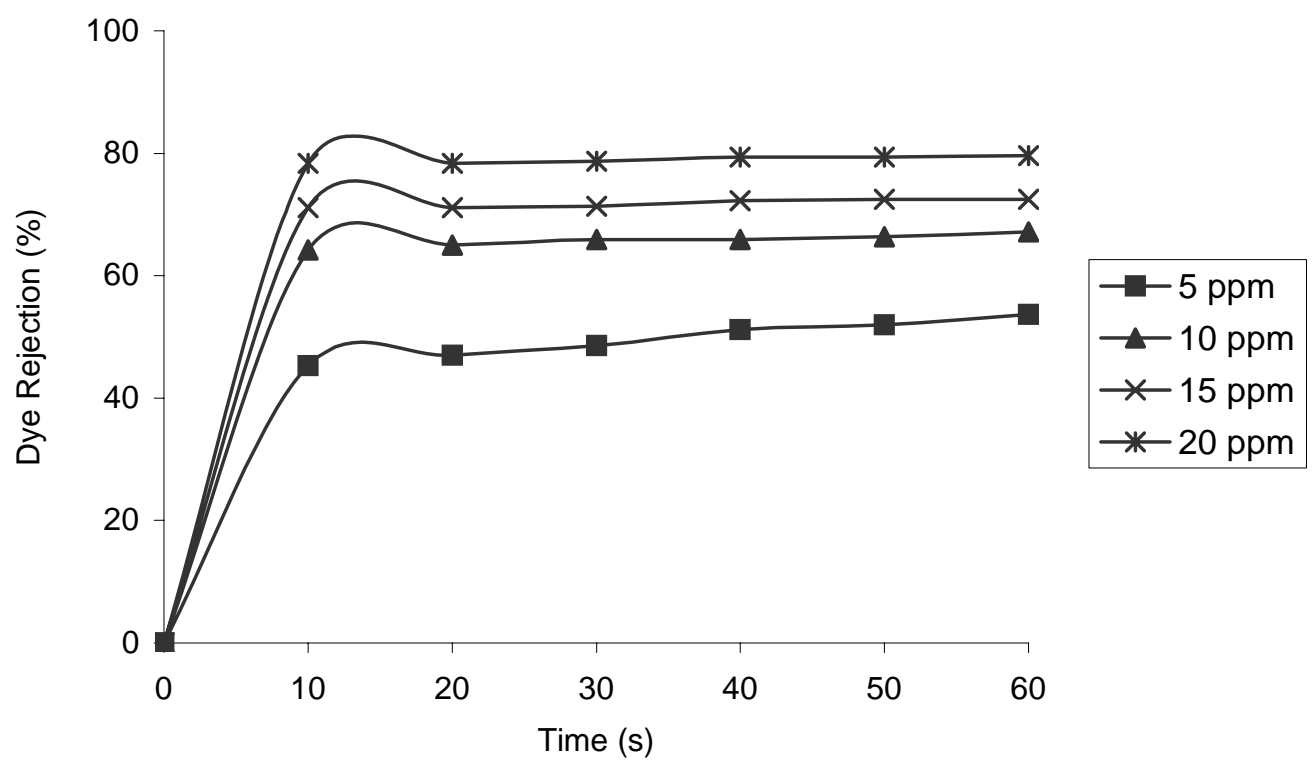

Fig. 4: Percentage of dye rejection at different concentration of dye versus time $(P=18.7$ psia, $\mathrm{pH}=7$ ) 
Table 3: Cake Resistance, $R_{C}$ at different concentration of dye $(P=18.7 \mathrm{psia}, \mathrm{pH}=7)$

\begin{tabular}{cc}
\hline Dye concentration $(\mathbf{p p m})$ & Cake resistance, $\boldsymbol{R}_{C} \times \mathbf{1 0}^{\mathbf{- 1 0}} \mathbf{( \mathbf { m } ^ { - \mathbf { 1 } } )}$ \\
\hline 5 & 4.060 \\
10 & 4.307 \\
15 & 4.419 \\
20 & 4.665 \\
\hline
\end{tabular}

\subsection{Effect of transmembrane pressure}

The experiment data for average flux and average percentage of dye rejection at different pressure are shown in Table 4 . The average flux was slightly increased from $1.984 \times 10^{-3}$ $\mathrm{m}^{3} / \mathrm{m}^{2} \mathrm{~s}$ to $2.444 \times 10^{-3} \mathrm{~m}^{3} / \mathrm{m}^{2} \mathrm{~s}$ as the transmembrane pressure increased from $16.2 \mathrm{psia}$ to 17.2 psia, while percentage of dye rejection was slightly decreased from $81.34 \%$ to $74.88 \%$. As stated in membrane separation theory, flux is expected to increase accordingly with an increasing in feed pressure (solution-diffusion model). The increase in feed pressure will increase the driving force, overcoming the membrane resistance [5]. Therefore, increasing the pressure would force more water to pass through the membrane which would result in the higher permeate flux recorded at 17.2 psia compared to 16.2 psia [8].

Table 4: Average flux and average rejection at different transmembrane pressure $\left(C_{\text {in }}=10\right.$ ppm, $\mathrm{pH}=7$ )

\begin{tabular}{ccc}
\hline Transmembrane pressure (psia) & Average flux $\times \mathbf{1 0}^{\mathbf{3}}\left(\mathbf{m}^{\mathbf{3}} / \mathbf{m}^{\mathbf{2}} \mathbf{. s}\right)$ & Average rejection (\%) \\
\hline 16.2 & 1.984 & 81.34 \\
17.2 & 2.444 & 74.88 \\
18.2 & 2.651 & 65.76 \\
\hline
\end{tabular}

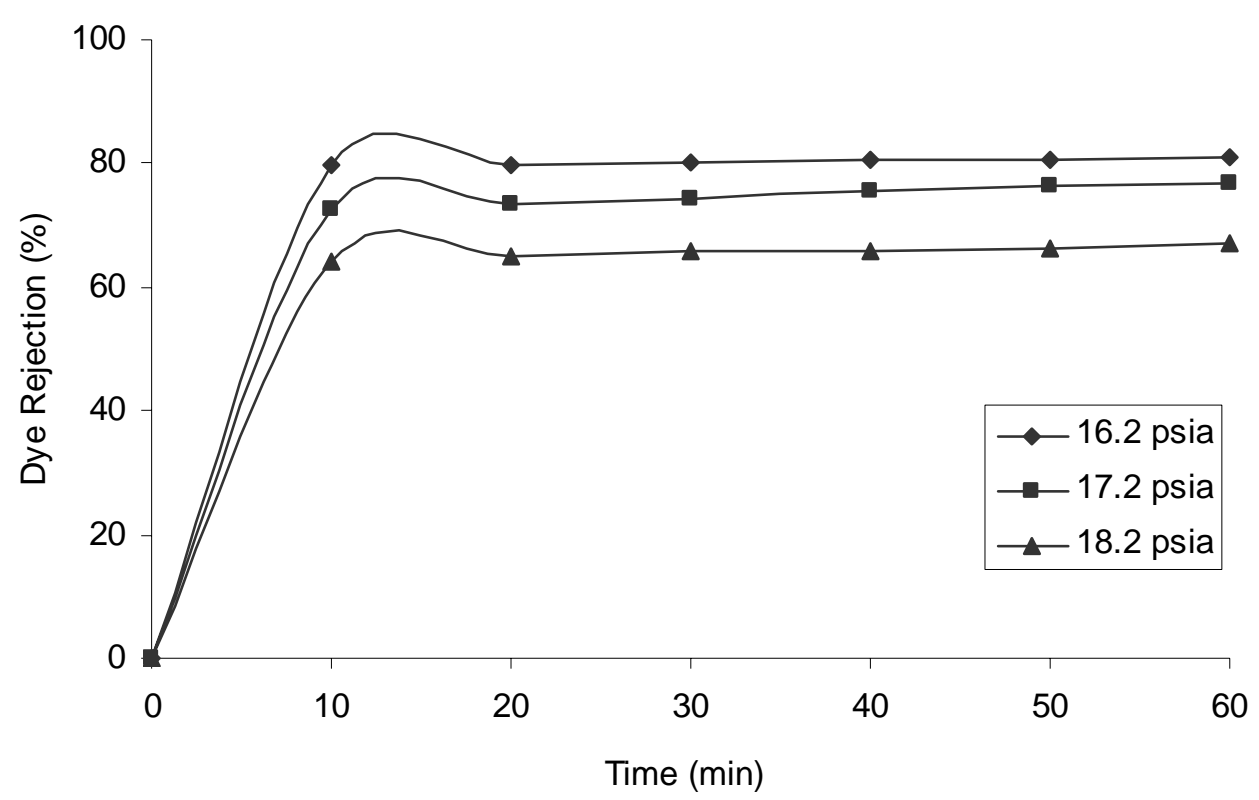

Fig. 5: Percentage rejection of dye at different transmembrane pressure versus time $\left(C_{i n}=10\right.$ ppm, $\mathrm{pH}=7$ ) 
Figure 5 shows the pattern of rejection at different transmembrane pressure versus time. For pressure 16.2 psia, the increment of rejection increased from $79.79 \%$ to $81.06 \%$. The increment is about $1 \%$ in one hour. Further increased of the applied pressure gave significant increment of rejection. It can be observed then at pressure18.2 psia, the percentage rejection increased from $64.22 \%$ to $67.17 \%$. From the data we can observed that the increment is about $5 \%$ in one hour. Overall, it can be concluded that the higher pressure difference, the higher would be the driving force which pushed the particles through the membrane pore. Thus, the formation of cake on the membrane surface would be minimized and lowered the percentage of rejection.

\subsection{Effect of $\mathbf{p H}$}

Table 5 shows the average flux and the average rejection for crossflow ultrafiltration at different $\mathrm{pH}$ of feed concentrations. From the table we can observed that the permeate flux was highest at $\mathrm{pH}$ 4. The higher flux is noticeable within the acidic $\mathrm{pH}$. This is because at lower $\mathrm{pH}$, effect of concentration polarization and membrane fouling can be minimized [8]. As we can see, at $\mathrm{pH} 7$ the average flux was lowest compared to the rest but highest percentage of rejection. At the rest, the average rejection was found to be close to each other.

Table 5: Average flux and average rejection at different $\mathrm{pH}\left(C_{\text {in }}=10 \mathrm{ppm}, \mathrm{P}=19.7 \mathrm{psia}\right)$

\begin{tabular}{|c|c|c|}
\hline Dye pH & Average flux $\times 10^{3}\left(\mathrm{~m}^{3} / \mathrm{m}^{2} . \mathrm{s}\right)$ & Average rejection (\%) \\
\hline 4 & 2.888 & 81.83 \\
\hline 6 & 2.767 & 81.97 \\
\hline 7 & 2.651 & 85.34 \\
\hline 8 & 2.779 & 82.18 \\
\hline 10 & 2.807 & 78.88 \\
\hline
\end{tabular}

The time-dependent fluxes of the experiment are plotted in Fig. 6. The figure shows how the flux decreased with time at different $\mathrm{pH}$ of dye. The influence of acid or base in $\mathrm{pH}$ study shows the same pattern of flux against time.

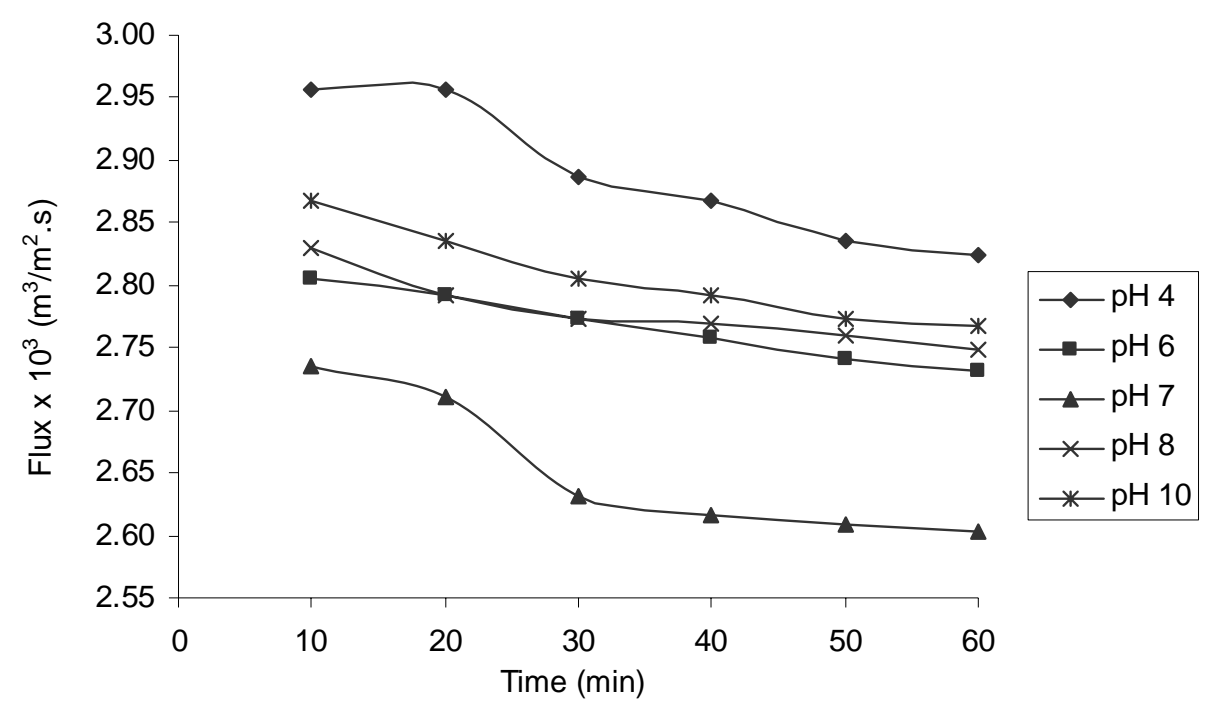

Fig. 6: Flux at different feed $p H$ versus time $\left(C_{i n}=10\right.$ ppm, $P=19.7$ psia $)$ 
Figure 7 shows the pattern of rejection at different feed $\mathrm{pH}$ versus time. Generally, the percentages of the rejection increased with time. For the variation of $\mathrm{pH}$ from $\mathrm{pH} 4$ to $\mathrm{pH} 10$, the rejection at different $\mathrm{pH}$ values of feed were quite similar. There is no significant increment of rejection through the feed in one hour experiment. The highest rejection occurred at neutral $\mathrm{pH}$ and the lowest at $\mathrm{pH} 10$.

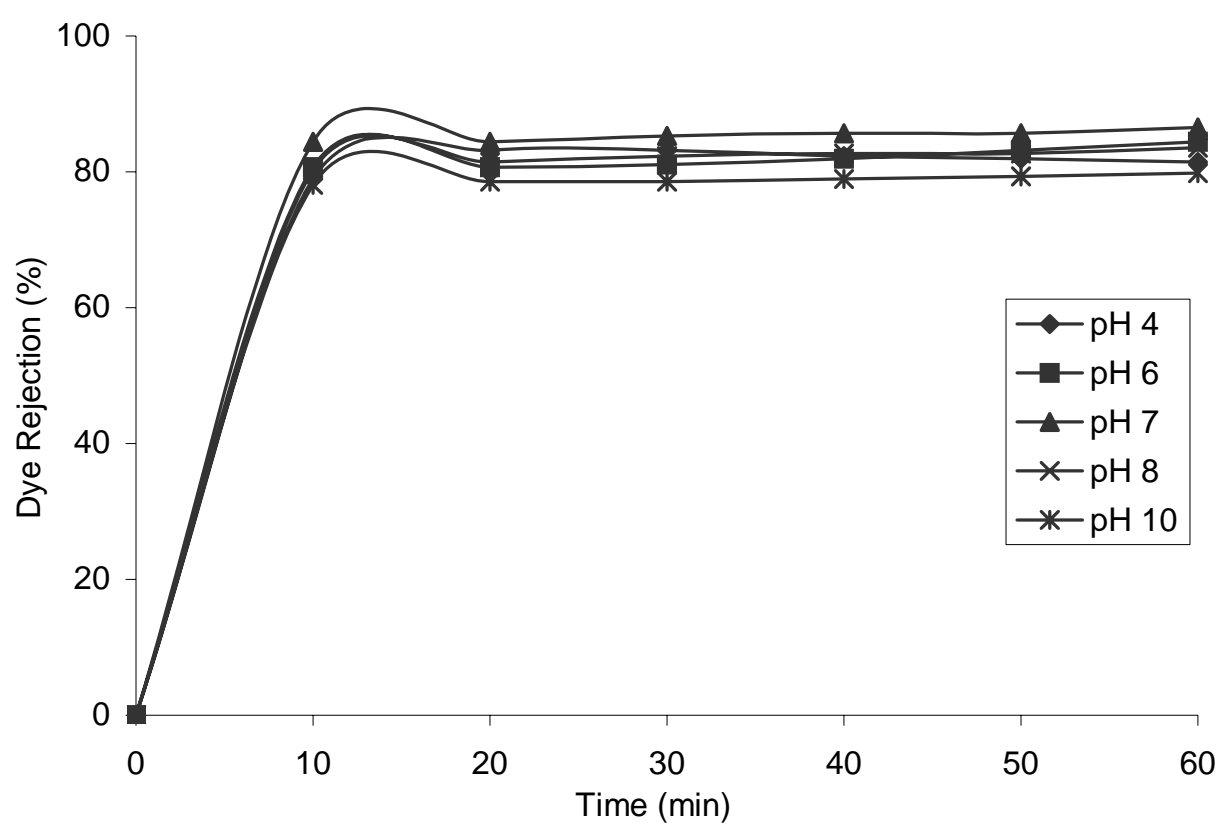

Fig 7: Percentage of dye rejection at different feed $\mathrm{pH}$ versus time $\left(C_{\text {in }}=10 \mathrm{ppm}, P=19.7 \mathrm{psia}\right)$

\section{CONCLUSION}

Crossflow Ultrafiltration membrane separation could be considered as one of the promising technology for the treatment of textile wastewater. GN ultrafiltration polymeric membrane has been tested with Direct-15 dye to determine the permeate flux and percentage of dye removal at different operating conditions. The feed concentration, the operating pressure and the $\mathrm{pH}$ of dye were the important parameter which is going to give an effect on the filtration process. As a result, feed concentration played a significant role in crossflow ultrafiltration membrane separation. The average flux decreased with increasing the feed concentration and the average rejection vice versa. At higher feed concentration, cake formation on the membrane surface was found to be dominant and contribute to membrane fouling. Increase the operating pressure will increase the flux rate and at the same time reduced the percentage rejection. The highest flux was observed at $\mathrm{pH}$ 4. This preliminary study showed that the ultrafiltration membrane has a feasibility to remove dye from wastewater.

\section{REFERENCES}

1. Tan, B.H., Teng, T.T., and Omar, A.K.M. (2000), Removal of dyes and industrial dye wastes by magnesium chloride, Wat. Res., vol. 34(2), pp. 597-601.

2. Ahmad, A.L., Harris, W.A., and Syafiie, Ooi.B.S. (2002), Removal of dye from wastewater of textile industry using membrane technology, Journal Teknologi 36(F), pp. 31-44. 
3. Chakraborty, S., Purkait, M.K., DasGupta, S., De, S., and Basu, J.K. (2003), Nanofiltration of textile plant effluent for color removal and reduction in COD, Separation and Purification Technology, vol. 31, pp. 141-151.

4. Koyuncu, I. (2002), Reactive dye removal in dye/salt mixtures by nanofiltration membranes containing vinylsulphone dyes: Effect of feed concentration and cross flow velocity, Desalination, vol. 143, pp. 243-253.

5. Tang, C., and Chen, V. (2002), Nanofiltration of textile wastewater for water reuse, Desalination, vol. 143, pp. 11-20.

6. Woerner, D.L. (2003), Membrane Technology in Textile Operations, Acessed: 27 October 2003, http://www.p2pays.org/ref/04/03269.pdf

7. Jiraratananon, R., Sungpet, A., and Luangsowan, P. (2000), Performance evaluation on nanofiltration membranes for treatment of effluents containing reactive dye and salt, Desalination, vol. 130, pp. 177-183.

8. Ahmad, A.L., Bhatia, S., and Ibrahim, N. (2004), Removal of suspended solids and residual oil using membrane separation technology, Regional Symposium On Membrane Science \& Technology, April 2004, pp. 21-25.

9. Ahmad, A.L. and Harris, W.A. (2000), Microfiltration recovery of dyes from wastewater of Batik industry, Seminar Persekitaran 2000.

10. Akbari, et al. (2002), Treatment of textile dye effluents using a new nanofiltration membrane photografted, Desalination, vol. 149, pp. 101-107.

11. Petrov, Stoycher (2003), Ultrafiltration purification of waters contaminated with bifunctional reactive dyes, Desalination, vol. 154, pp. 247-252.

12. Ciardelli, G., et al. (2000), Membrane separation for wastewater reuse in the textile industry, Journal of Resources, Conservation and Recycling, vol. 31, pp. 189-197. 